\title{
Pulsed Umbilical Artery Doppler Ultrasound Findings in Management of High-Risk Term Pregnant Women during Labour
}

\author{
Noora E. Hamid1', Shahla K. Alalaf², Namir G. Al-Tawil ${ }^{3}$ \\ ${ }^{1}$ Maternity Teaching Hospital, Erbil City, Kurdistan Region, Iraq \\ ${ }^{2}$ Department of Obstetrics and Gynaecology, College of Medicine, Hawler Medical University, Erbil City, Kurdistan Region, Iraq \\ ${ }^{3}$ Department of Community Medicine, College of Medicine, Hawler Medical University, Erbil City, Kurdistan Region, Iraq \\ Email: Shahla_alaf@yhoo.com
}

How to cite this paper: Hamid, N.E., Alalaf, S.K. and Al-Tawil, N.G. (2017) Pulsed Umbilical Artery Doppler Ultrasound Findings in Management of High-Risk Term Pregnant Women during Labour. Open Journal of Obstetrics and Gynecology, 7, 139146.

http://dx.doi.org/10.4236/ojog.2017.71015

Received: December 20, 2016

Accepted: January 15, 2017

Published: January 18, 2017

Copyright $\odot 2017$ by authors and Scientific Research Publishing Inc. This work is licensed under the Creative Commons Attribution International License (CC BY 4.0).

http://creativecommons.org/licenses/by/4.0/

(c) () Open Access

\begin{abstract}
Purpose: Intrapartum Doppler velocimetry is a non-invasive investigation method. This method is useful for evaluating the pathophysiological mechanisms underlying changes in fetal heart rate. This study aimed to determine the usefulness of Doppler ultrasound findings during labor in high-risk women on determining the mode of delivery and outcome of the newborn. Methods: A cross-sectional study was conducted from January 1, 2015 to December 31, 2015 on 100 high-risk pregnant women during labor. The study was performed in the Maternity Teaching Hospital in Erbil City, Kurdistan Region, Iraq. Results: The majority of women (77\%) had a normal end-diastolic blood flow pattern through the umbilical artery. A total of $76.9 \%$ of those with abnormal Doppler results had a Cesarean delivery compared with only $9.5 \%$ of those with normal Doppler results $(p<0.001)$. The rate of early neonatal death was significantly higher $(15.4 \%)$ in women with abnormal Doppler results than in those with normal Doppler results $(1.4 \%, p=0.016)$. Admission to the neonatal intensive care unit was significantly more frequent in women with abnormal Doppler results than in those with normal Doppler results $(61.5 \%$ vs. $17.6, p<0.001)$. The same pattern was seen in the Apgar score in the first $(p=0.07)$ and fifth minutes $(p=$ 0.01 ). Conclusions: Abnormal umbilical artery Doppler ultrasound findings in highrisk pregnancies for women in labor are associated with increased rates of emergency cesarean sections and a poor outcome of the newborn.
\end{abstract}

\section{Keywords}

Doppler Ultrasound, Velocimetry, Early Neonatal Death, Umbilical Artery

\section{Introduction}

The goal of intrapartum fetal surveillance is to contribute to improvement of intrapar- 
tum fetal monitoring. This reduces the burden of perinatal mortality and long-term morbidities, while also avoiding unnecessary obstetric interventions [1].

The current evidence on fetal health surveillance during the antenatal and intrapartum period has shown that improvement in fetal outcome as a result of these modulations is difficult to document. This is because of variations in the interpretation of fetal monitoring tests, especially electronic fetal heart monitoring. There is variation in the obstetric interventions that are used when abnormal results are present and a lack of standardization of important outcomes [2]. There is also limited evidence of randomized, clinical trials that support daily practice modalities that can be used for assessment of fetal wellbeing during the antenatal and intrapartum periods. The only testing modality for which there is Level 1 evidence is the use of umbilical artery Doppler for fetal surveillance in growth restricted fetuses [3].

Intrapartum Doppler velocimetry is a non-invasive investigation method. This method is useful for evaluating the pathophysiological mechanisms related to fetal heart changes during labor. Concurrent use of this method with other investigations allows understanding of the physiology and pathophysiology of feto-placental changes and fetal adaptive mechanisms, especially in acute fetal asphyxia [4]. There are currently few published articles regarding the utility of Doppler examinations during labor. This is because of certain technical difficulties of this procedure during labor. Intrapartum uterine contractions cause changes in maternal circulation parameters and maternal respiratory movements, which are more frequent during uterine contractions. With reduced amniotic fluid volume, the fetal skull deeply protrudes in to the pelvis during labor. All of these variables are related to the difficulty of continuous recording of the Doppler signal [5].

This study aimed to determine the usefulness of Doppler ultrasound findings on determining the mode of delivery and outcome of the newborn.

\section{Methods}

\section{Patients and Design of the Study}

A cross-sectional study was conducted from January 1, 2015 to December 31, 2015 on 100 high-risk pregnant women during labor. The study was performed in the Maternity Teaching Hospital in Erbil City, Kurdistan Region, Iraq. The Maternity Teaching Hospital is a 260-bed tertiary care referral hospital and is the main public hospital in Erbil City, with an average annual delivery rate of 27,000 . This hospital serves the population from the middle and lower socioeconomic groups.

A convenience sample of 100 women (in labor) with a viable singleton pregnancy and a gestational age of 37 - 41 weeks. We included women with hypertensive disorders, diabetes mellitus, oligohydramnios, suspected intrauterine growth retardation, decreased fetal movements, and postdate pregnancy. All of the participants were seen for the first time in the labor room and diagnosed to be in labor. They had no history of antenatal follow-up. Pregnant women with multiple pregnancies, fetuses with congenital abnormalities, premature rupture of the membranes, intrauterine fetal death, known fetal cardiovascular system anomalies, and a history of smoking were excluded.

A full history was taken regarding the age of the pregnant women, obstetric history, 
gestational age at delivery (measured by the last menstrual period and confirmed by ultrasound in early pregnancy), any antenatal complication, and hospitalization for either medical or surgical causes.

Abdominal and vaginal examinations were performed for all participants. Management of labor and the decision for the mode of the delivery were performed depending on the history, abdominal and vaginal examinations, and intrapartum umbilical artery Doppler ultrasound findings. Neonates were initially assessed by means of the Apgar score at 1 and 5 minutes after delivery. Neurological assessment for signs of hypoxia was performed in the neonates, all within the first 48 hours of delivery by a pediatrician on call. Data were collected using a questionnaire that was designed by the researchers. Weight of the newborn, Apgar score, admission to the neonatal care unit, and the mode of delivery were recorded in the questionnaire.

Blood flow velocity waveforms of the umbilical arteries was performed using ultrasound (HD 11XE; Philips, The Netherlands), with a trans-abdominal curvilinear transducer of 3.5 MHz. To reduce the variation in measurements of Doppler recordings, all of the women were evaluated by the same sonographer (in the Ultrasound and X-Ray Department of the Maternity Teaching Hospital), who was an expert in this field.

During Doppler studies, the mother was asked to lie down in a semi recumbent position with a slight left lateral tilt. This was performed to minimize the risk of supine hypotension syndrome due to caval compression by the gravid uterus. The Doppler index was measured in a free-floating loop of the umbilical cord during the absence of fetal hiccups or excessive movement, a regular fetal heart rate, and no breathing movements. The angle of the fetal Doppler insonation was maintained at less than $45^{\circ}$. Each value was the average of three measurements.

The umbilical artery waveform was evaluated by measuring blood flow velocity at peak systole and peak diastole. These values were then computed to derive the resistance index (RI). This index was computed by measuring the peak of systole and then dividing it by the sum of measurements at peak systole and diastole as follows: RI= systole/(systole + diastole) [6]. The cutoff point of 0.6 for RI was considered as normal.

Four types of waveform were recognized during the examination: (type I) normal RI with blood flow present during diastole; (type II) abnormal RI with reduced blood flow during diastole; (type III) abnormal RI with absent blood flow during diastole; and (type IV) abnormal RI with reversed blood flow during diastole.

Wave form Doppler velocimetry was performed once during the course of labor. The decision of the mode of delivery was dependent on the findings of Doppler ultrasound in addition to findings of the pelvis and a general examination of the patient. This decision was made by the obstetrician on call.

\section{Results}

One hundred women were participated in this study. The mean age $( \pm S D)$ of the women was $28.98 \pm 6.54$ years, with a median age of 29 years (range: $15-45$ years). A total of $39 \%$ of the sample was nulliparous women. The mean parity was $1.45 \pm 1.76$, with a median parity of 1 (range: $0-8$ children) (Table 1 ). Approximately two thirds of 
Table 1. Distribution of sample size by age, parity, mode of delivery, and indications for cesarean delivery.

\begin{tabular}{|c|c|c|c|}
\hline Studied variables & Categories & No. (and \%) & Mean (+SD) \\
\hline \multirow{5}{*}{ Age (years) } & $<20$ & 5 & $28.98+6.54$ \\
\hline & $20-24$ & 20 & \\
\hline & $25-29$ & 27 & \\
\hline & $30-34$ & 28 & \\
\hline & $\geq 35$ & 20 & \\
\hline \multirow{3}{*}{ Parity } & Zero & 39 & $1.45+1.76$ \\
\hline & $1-2$ & 40 & \\
\hline & $\geq 3$ & 21 & \\
\hline \multirow{3}{*}{ Mode of delivery } & Vaginal & 64 & \\
\hline & CS & 27 & \\
\hline & Induction of labor & 9 & \\
\hline \multirow[b]{2}{*}{ Outcome } & Alive & 95 & \\
\hline & Early neonatal death & 5 & \\
\hline Total & & 100 & \\
\hline
\end{tabular}

CS: Cesarean section.

the women (64\%) delivered vaginally, and $5 \%$ of fetal outcomes ended with early neonatal death (Table 1$)$.

The main indication of cesarean delivery (48.1\%) was based on the results of abnormal Doppler and 22.2\% were due to fetal distress (Table 2).

With regard to antenatal complications of the participants, $64 \%$ had pre-eclampsia and $14 \%$ had diabetes during pregnancy, $5 \%$ had antepartum hemorrhage associated with decreased fetal movements while $17 \%$ of women presented with postdate pregnancies.

A total of $77 \%$ of women had normal umbilical blood flow, while $23 \%$ had abnormal end-diastolic blood flow (Table 3).

A higher proportion of women with abnormal Doppler findings delivered by Caesarean section than did those with normal Doppler findings (Table 4). The proportion of early neonatal death was significantly higher in women with abnormal Doppler findings compared with those with normal Doppler findings $(p=0.01)$. The rate of neonatal intensive care unit admission was significantly higher in women with abnormal Doppler findings than in those with normal Doppler findings $(p<0.001)$. A higher proportion of women with abnormal Doppler findings had a low Apgar score (5 minutes after delivery) compared with those with normal Doppler findings ( $p=0.01$, Table 4).

Write "Magnetization $(\mathrm{A} / \mathrm{m})$ " or "Magnetization $\left(\mathrm{A} \cdot \mathrm{m}^{-1}\right)$ ", not just " $\mathrm{A} / \mathrm{m}$ ". Do not label axes with a ratio of quantities and units. For example, write "Temperature (K)", not "Temperature/K". 
Table 2. Indications of cesarean delivery.

\begin{tabular}{cccc}
\hline & Categories & No. & $\%$ \\
\hline Indication of CS & Fetal distress & 6 & 22.2 \\
& Meconium stained liquor & 3 & 11.1 \\
& Abnormal Doppler & 13 & 48.1 \\
& Others & 5 & 18.5 \\
& 27 & 100 \\
\hline
\end{tabular}

CS: Caesarean section.

Table 3. Doppler ultrasound findings (end-diastolic blood flow).

\begin{tabular}{ccc}
\hline Results of Doppler & No. & $\%$ \\
\hline Normal & 77 & 77.0 \\
Reduced & 18 & 18.0 \\
Absent & 2 & 2.0 \\
Reversed & 3 & 3.0 \\
Total & 100 & 100.0 \\
\hline
\end{tabular}

Table 4. Associations of doppler results with the mode of delivery and outcome of delivery.

\begin{tabular}{|c|c|c|c|c|c|}
\hline & \multicolumn{4}{|c|}{ Doppler results } & \multirow{3}{*}{$P$} \\
\hline & \multicolumn{2}{|c|}{ Normal } & \multicolumn{2}{|c|}{ Abnormal (EDBF) } & \\
\hline & No. & $\%$ & No. & $\%$ & \\
\hline \multicolumn{6}{|c|}{ Mode of delivery } \\
\hline Vaginal & 68 & 88.3 & 5 & 21.7 & \\
\hline CS & 9 & 11.7 & 18 & 78.3 & $<0.001$ \\
\hline \multicolumn{6}{|c|}{ Outcome } \\
\hline Alive & 76 & 98.7 & 19 & 82.6 & \multirow{2}{*}{$0.01^{*}$} \\
\hline Early neonatal death & 1 & 1.3 & 4 & 17.4 & \\
\hline \multicolumn{6}{|c|}{ NICU admission } \\
\hline No & 62 & 80.5 & 9 & 39.1 & \multirow{2}{*}{$<0.001$} \\
\hline Yes & 15 & 19.5 & 14 & 60.9 & \\
\hline \multicolumn{6}{|c|}{ APGAR 1 minute } \\
\hline$<7$ & 37 & 48.1 & 16 & 69.6 & \multirow{2}{*}{0.070} \\
\hline$\geq 7$ & 40 & 51.9 & 7 & 30.4 & \\
\hline \multicolumn{6}{|c|}{ APGAR 5 minute } \\
\hline$<7$ & 1 & 1.3 & 4 & 17.4 & \multirow{2}{*}{$0.010^{*}$} \\
\hline$\geq 7$ & 76 & 98.7 & 19 & 82.6 & \\
\hline Total & 77 & 100 & 23 & 100 & \\
\hline
\end{tabular}

CS: Cesarean section NICU: Neonatal intensive care unit. 


\section{Discussion}

The main principle of intrapartum fetal assessment is to detect fetal distress early before any permanent damage occurs. Besides the traditional method using non-stress and contraction stress tests, Doppler indices are a non-invasive predictor of adverse perinatal outcomes in complicated pregnancies. Doppler velocimetry is a rapid procedure and provides important information on the hemodynamic situation of the fetus. This procedure is also an efficient diagnostic test of fetal risk that is helpful in management of high-risk pregnancies [7].

The diagnostic efficacy of the umbilical arterial systole/diastole ratio in high-risk pregnancy appears to be more sensitive, but less specific, than the non-stress test in predicting fetal growth restriction and fetal distress [8].

The current study showed that the use of umbilical artery Doppler sonography in a high-risk group for women in labor was a good predictor of postnatal outcome and making decisions on the mode of delivery. We found that women with abnormal Doppler findings had a higher rate $(76.9 \%)$ of cesarean delivery than did those with normal Doppler findings (9.5\%). A study by Urmila and Beena showed that the proportion of women who had emergency cesarean delivery was higher in the high-risk group with abnormal Doppler measurements than in women with normal Doppler measurements who had cesarean delivery (78\% versus $24 \%$ ) [9]. Singh et al. showed that patients with abnormal Doppler indices had a higher incidence of cesarean delivery (44\%) than did those with normal Doppler findings, which is consistent with our results [10].

The rate of early neonatal death in our study was significantly higher in women with abnormal Doppler findings than in those with normal Doppler findings $(15.4 \%$ vs. $1.4 \%)$, which is consistent with the results of Urmila and Beena. They found that the rate of neonatal death in women with abnormal Doppler findings was $14 \%$, where as those with normal Doppler findings had no neonatal death [9]. A prospective study was performed in 50 high-risk pregnant women who had pre-eclampsia who were followed up until delivery and perinatal outcomes were recorded [10]. This study showed that women with abnormal Doppler indices had a significantly higher rate of neonatal death (26\%) than did women with normal Doppler findings [10].

In our study, the rate of admission to the neonatal intensive care unit was significantly higher in women with abnormal Doppler findings compared with those with normal Doppler findings. The same pattern was observed regarding the Apgar score in the first and fifth minutes and an abnormal Doppler outcome was associated with a poor outcome of delivery. A prospective study conducted by Urmila and Beena showed that the rates of neonates who were admitted to the nursery care unit and neonates with a low Apgar score were higher in women with abnormal Doppler findings than in those with normal Doppler findings [9].

Doppler ultrasound use during labor should also preceded by its use during pregnancy in high-risk groups of pregnant women. This is because Doppler ultrasound is associated with a significant reduction in antenatal admission, induction of labor, elective delivery (induction of labor and elective cesarean delivery) and cesarean delivery, and it decreases perinatal death [11]. Our study showed that Doppler wave form indices 
during labor were a good indicator for fetal outcome after delivery. Future studies should use Doppler ultrasound early in labor and during follow-up of women during the course of labor to diagnose any distress early and prevent stillbirth.

A major limitation of the current study was the scarcity of published articles regarding the use of umbilical artery Doppler ultrasound for women at high risk. Umbilical artery Doppler ultrasonography is recommended to be an integral component of fetal surveillance during labor in addition to other methods of fetal assessment during labor.

Future research should be conducted in a larger sample size using pulsatility Doppler ultrasound versus cardiotocography to assess the validity of results.

\section{Conclusion}

Abnormal umbilical artery Doppler ultrasound findings in high-risk pregnancies of women in labor are associated with an increased number of emergency cesarean deliveries and adverse fetal outcomes.

\section{Compliance with Ethical Standards}

Funding: This study was funded by the Iraqi Board for Medical Specialization. The funding process was only for academic purposes.

Conflict of Interest: The authors declare that they have no conflict of interest.

\section{Ethical Approval}

The study conforms to the ethics and standards currently applied by the ethics committee in the scientific counsel of Obstetrics and Gynecology Specialization/Iraqi Board for Medical Specialization, and these are in accordance with the 1964 Helsinki declaration.

The study was approved by the Institutional review board of the Maternity Teaching Hospital. Informed consent: Written formal informed consent was provided by all of the participants.

\section{References}

[1] Ayres-de-Campos, D. and Arulkumaran, S. (2015) FIGO Consensus Guidelines on Intrapartum Fetal Monitoring: Introduction. IJOG, 131, 3-4.

[2] Barrett, J.F., Jarvis, G.J., Macdonald, H.N., Buchan, P.C., Tyrrell, S.N. and Lilford, R.J. (1990) Inconsistencies in Clinical Decisions in Obstetrics. Lancet, 336, 549-551. https://doi.org/10.1016/0140-6736(90)92097-2

[3] Williams, K.P., Farquharson, D.F., Bebbington, M., Dansereau, J., Galerneau, F., Wilson, R.D., et al. (2003) Screening for Fetal Well-Being in a High-Risk Pregnant, Population Comparing the Non-Stress Test with Umbilical Artery Doppler Velocimetry: A Randomized Controlled Clinical Trial. American Journal of Obstetrics \& Gynecology, 188, 13661371. https://doi.org/10.1067/mob.2003.305

[4] Mihu, D., Diculescu, D., Costin, N., Mihu, C.M., Blaga, L., Ciortea, R. and Măluțan, A. (2011) Applications of Doppler Ultrasound during Labor. Medical Ultrasonography, 13, 141-149.

[5] Cheng, Y.W., Hopkins, L.M. and Caughey, A.B. (2004) How Long Is Too Long: Does a Prolonged Second Stage of Labor in Nulliparous Women Affect Maternal and Neonatal 
Outcomes? American Journal of Obstetrics \& Gynecology, 191, 933-938. https://doi.org/10.1016/j.ajog.2004.05.044

[6] Keats, T.E. and Sistrom, C. (2001) Atlas of Radiologic Measurement. Gulf Professional Publishing.

[7] Li, H., Gudmundsson, S. and Olofsson, P. (2003) Uterine Artery Bloodflow Velocity Waveforms during Uterine Contractions. Ultrasound in Obstetrics \& Gynecology, 22, 578-585. https://doi.org/10.1002/uog.921

[8] Trudinger, B.J., Giles, W.B., Cook, C.M., Bombardieri, J. and Collins, L. (1985) Fetal Umbilical Artery Flow Velocity Waveforms and Placental Resistance: Clinical Significance. British Journal of Obstetrics and Gynaecology, 92, 23-30. https://doi.org/10.1111/j.1471-0528.1985.tb01044.x

[9] Urmila, S. and Beena, B. (2010) Triple Vessel Wave Pattern by Doppler Studies in Normal and High Risk Pregnancies and Perinatal Outcome. Journal of Obstetrics and Gynecology of India, 60, 312-316. https://doi.org/10.1007/s13224-010-0044-x

[10] Singh, M., Sharma, A. and Singh, P. (2013) Role of Doppler Indices in the Prediction of Adverse Perinatal Outcome in Preeclampsia. National Journal of Medical Research, 3, 315318.

[11] Westergaard, H.B., Langhoff-Roos, J., Lingman, G., Marsál, K. and Kreiner, S. (2001) A Critical Appraisal of the Use of Umbilical Artery Doppler Ultrasound in High-Risk Pregnancies: Use of Meta-Analyses in Evidence-Based Obstetrics. Ultrasound in Obstetrics \& Gynecology, 17, 466-476. https://doi.org/10.1046/j.1469-0705.2001.00415.x

\section{Submit or recommend next manuscript to SCIRP and we will provide best service for you:}

Accepting pre-submission inquiries through Email, Facebook, LinkedIn, Twitter, etc. A wide selection of journals (inclusive of 9 subjects, more than 200 journals)

Providing 24-hour high-quality service

User-friendly online submission system

Fair and swift peer-review system

Efficient typesetting and proofreading procedure

Display of the result of downloads and visits, as well as the number of cited articles

Maximum dissemination of your research work

Submit your manuscript at: http://papersubmission.scirp.org/

Or contact ojog@scirp.org 